\title{
Fetal Doppler Study of Ductus Venosus to Assess Fetal Acidemia in IUGR
}

\author{
Anita Soundarapandian ${ }^{1}$, Senthil Anbumani ${ }^{2}$, Anusha Palaniswamy ${ }^{3}$ \\ ${ }^{1}$ Associate Professor, Department of Radiology, Saveetha Medical College, ${ }^{2}$ Assistant Professor, Department of Radiology, \\ ACS Medical College, ${ }^{3}$ Resident, Department of Radiology, Saveetha Medical College, India
}

Corresponding author: Senthil Anbumani, Department of Radiology, ACS Medical College, Chennai, India

DOI: 10.21276/ijcmsr.2018.3.2.35

How to cite this article: Anita Soundarapandian, Senthil Anbumani, Anusha Palaniswamy. Fetal Doppler study of ductus venosus to assess fetal acidemia in IUGR. International Journal of Contemporary Medicine Surgery and Radiology. 2018;3(2):B147-B151.

\section{A B S T R A C T}

Introduction: it is a known fact that significant perinatal mortality and morbidity is associated with intrauterine fetal growth restriction (IUGR). The morbidities range from low birth weight to intrauterine fetal demise. Fetal neurological damage is one of the most dreaded results of IUGR. Placental insufficiency is the most common cause of fetal growth restriction in today's scenario. The aim was early identification of fetal hemodynamic compromise, fetal hypoxemia and the dreaded fetal acidemia in established growth restricted fetuses. The aim was also to precisely recognize fetal hypoxia, assist the clinician in planning delivery before the onset of irreversible fetal academia and to see how well the fetal outcome correlated with the severity of our fetal Doppler indices.

Material and methods: 160 clinically and biometrically confirmed growth restricted fetuses underwent fetal Doppler study. Fetal abdominal circumference less than 5 th percentile and estimated fetal weight on or less than 10th percentile for that gestational age were considered as IUGR fetuses. Fetal Doppler was performed using a Philips color Doppler machine with a $3.5 \mathrm{MHz}$ convex probe. The umbilical artery, fetal middle cerebral artery and the fetal ductus venosus were sampled. The pulsatility indices were measured. Follow up of these fetuses were done and the perinatal outcome were obtained.

Results: The diagnosis of IUGR can be done with grey scale biometry. However the fetal hemodynamic status to assess for hypoxia and acidemia were possible only by fetal Doppler. By assessing the severity of the Doppler findings and accurate prediction of perinatal outcome was done.

Conclusion: By applying the grading of altered fetal Doppler indices, the fetus can be classified as hemodynamically stable, altered hemodynamic state, fetal hypoxia and fetal acidemia. By intervening before fetal acidemia sets in, the perinatal mortality can be drastically reduced.

Key Words: Fetal Acidemia, Fetal Hypoxemia, Diastolic Reversal, Ductus Venosus, Perinatal Outcome

\section{INTRODUCTION}

The incidence of intrauterine growth restriction is in the range of 3 to $10 \%$. It was way back in 1961, Warkany and co-workers set a few nomograms for fetal weight, head and abdominal circumferences ${ }^{1}$. This served as a base to define fetal growth restriction. In 1963, Gruenwald said that around one third of infants who had a low birth weight were secondary to "chronic placental insufficiency" . In 1963, Lubchenco and coworkers from Denver published the relationship of various gestational ages to the respective weights to establish norms for fetal biometry and growth at a particular gestational age ${ }^{3}$. It was Battagalia and Lubchenc who in 1967 , classified the $10^{\text {th }}$ centile as the cut off and said infants whose birth weight were below the gestational age are small for gestational age $\mathrm{a}^{4}$.

Manning and Hohler and Gardosi said that up to $60 \%$ of infants who were said to be small for gestational age were actually appropriately grown considering the maternal ethnic group,and weight, and are not low birth weight infants ${ }^{5}$. Small for gestational age should be when the birth weight is below fifth percentile was proposed by Seeds in $1984^{6}$. Usher and McLean projected that standards for fetal growth should be based on limits defined by \pm 2 standard deviations from normal limits. Clinically, this definition seemed most appropriate ${ }^{7}$, since adverse fetal outcomes were most marked when the birthweight was below the third percentile. In a study of more than a lakh deliveries at Parkland Hospital in 1999, Mclntire and Colleagues said the same, when they saw that there was a significant increase in both mortality and morbidity when the infant birth weights were at or below the third percentile ${ }^{8}$. A definitive and proportionate increase in both mortality and morbidity was seen as birth weight percentile falls below the third percentile. Owen and Colleagues in 1997 and Owen and Khan in 1998 reported that decreased rate of fetal growth in serial biometry is proportionate to caesarean sections done for fetal distress and significant fetal growth restriction ${ }^{9,10}$.

\section{MATERIAL AND METHODS}

This was a cross sectional observational study done over a 
period of two years from May 2015 to September 2017, after obtaining the approval of the Institutional review board. 160 recognized IUGR cases documented by both clinical assessment and serial ultrasound biometry done on interval basis were selected for the study.

\section{Inclusion criteria}

Singleton fetuses with established gestational age beyond 32 weeks were included in the study.

\section{Exclusion criteria}

Diagnosed congenital or chromosomal anomalies were excluded from the study. Multiple pregnancies were also excluded from the study. Patients with unknown dates were excluded from the study.

The machine used for Doppler was a Philips color Doppler machine with a $3.5 \mathrm{MHz}$ convex probe. An exhaustive obstetric history with emphasis on pregnancy induced hypertension, gestational diabetes and chronic maternal hypertension was taken. Prior obstetric history with emphasis on infant birthweight or perinatal demise was also obtained. The patients with fetal abdominal circumference less than 5 th percentile and fetal weight less than 10th percentile for that gestational age were selected for our study ${ }^{11}$. Initial scan was performed as the dating scan preferably in the first trimester. This was then followed by serial ultra-sounds. The growth scan was performed at around 32 to 36 weeks. The study cases were kept under scrutiny till the post natal period.

If the fetal Doppler was normal, the patients were monitored once in two weeks till confinement ${ }^{12}$. When the abnormality in fetal Doppler showed a severe hemodynamic instability such as absent or reversed umbilical artery flow, immediate termination of pregnancy was undertaken ${ }^{13}$.

Fetal Doppler studies were performed by sampling the umbilical artery, fetal middle cerebral artery and ductus venosus. Our study is based more on the significance of the ductus venosus.

A free loop of umbilical cord preferably in the midsegment or close to the placental insertion was located in the amniotic fluid, the longituidinal section was obtained by manipulating the probe and values were obtained.

A transverse section of the fetal head was obtained similar to the BPD plane, caudally angulated and color Doppler was switched to visualized the middle cerebral artery. The sample gate was placed on the mid portion of the horizontal segment of the MCA and the values were obtained.

An abdominal circumference section of the fetus was obtained, color Doppler was switched on, and the short vessel with turbulent flow and aliasing seen coursing from the umbilical vein to the IVC was identified and sampled.

The waveforms were recorded for a minimum of 8 to 10 cycles. Good quality waveforms with adequate amplitude and uniform pattern was an essential prerequisite. Once this was obtained, the image was freezed and the pulsatility indices were measured.

In the umbilical artery, adequate diastolic flow indicated normal Doppler. If the umbilical artery diastolic flow is reduced, absent or reversed it indicated fetal hemodynamic compromise in increasing severity ${ }^{14-17}$.

In the middle cerebral artery, a low diastolic flow indicates normality. Increased diastolic flow indicated fetal compensation, with preferential flow of blood to the fetal brain $^{18}$. At this time of fetal hemodynamic compromise, there is cerebro placental ratio reversal. The cerebroplacental ratio is the ratio of the pulsatility index of MCA to the pusatlity index of the umbilical artery. In hemodynamically stable fetuses, this ration is always more than one. In a compensated fetus, this ration becomes less than one.

In the fetal ductus venosus the flow pattern is a triphasic pattern, with S, D and A waves. In a normal fetus all three points should be in a forward direction and therefore above the baseline ${ }^{19,20}$. This is in contrast to the flow in the other veins such as IVC where the A wave is below the baseline.

\section{Timing the obstetric intervention}

If the fetal Doppler was normal, the patients were monitored once in two weeks till confinement. When the abnormality in fetal Doppler showed a severe hemodynamic instability such as absent or reversed umbilical artery flow, immediate termination of pregnancy was undertaken.

When the Doppler abnormality was intermediate such as a reduced umbilical artery diastolic flow, if the background fetal maturity was adequate, the patient was taken up for pregnancy termination. In the patients where adequate fetal maturity had not been achieved, close clinical monitoring of the patient with non stress tests and biophysical profiles were done on a daily basis. Patient was intervened if these tests showed any abnormality at any time.

When there was cerebroplacental reversal which indicated preferential shunting of blood to the fetal brain, the pregnancy was immediately terminated.

Perinatal outcome was recorded as intrauterine death, neonatal death, Apgar and infant birthweight Outcome of pregnancy was recorded in detail including intrauterine demise, neonatal death, birth weight.

\section{RESULTS}

Our study was done on 160 third trimester women with sonographically confirmed growth restricted fetuses and

\begin{tabular}{|l|c|c|}
\hline Total No of IUGR Cases & $\mathbf{1 6 0}$ & $\mathbf{\%}$ \\
\hline Normal Doppler & 18 & 11.2 \\
\hline Abnormal Doppler & 142 & 88.8 \\
\hline
\end{tabular}

Table-1: Amongst the 160 patients subjected for fetal Doppler,

Doppler abnormalities were observed in $88.8 \%$ patients

\begin{tabular}{|l|l|}
\hline Grade & Doppler findings \\
\hline 0 & Normal Doppler \\
\hline 1 & $\begin{array}{l}\text { Increased umbilical artery PI without other Doppler } \\
\text { abnormalities }\end{array}$ \\
\hline 2 & $\begin{array}{l}\text { Increased umbilical artery PI with reduced middle } \\
\text { cerebral artery PI - cerebroplacental reversal }\end{array}$ \\
\hline 3 & $\begin{array}{l}\text { Absent/reversed diastolic flow in umbilical artery } \\
\text { with decreased middle cerebral artery PI }\end{array}$ \\
\hline 4 & $\begin{array}{l}\text { Absent/reversed diastolic flow in umbilical artery } \\
\text { with increased middle cerebral artery PI }\end{array}$ \\
\hline 5 & Altered 'a' wave in ductus venosus \\
\hline Table-2: Grading of the Doppler findings in ascending order of \\
severity
\end{tabular}




\begin{tabular}{|c|c|c|c|}
\hline \multicolumn{2}{|c|}{ GRADES } & \multirow{2}{*}{$\begin{array}{c}\begin{array}{c}\text { Number of } \\
\text { patients }\end{array} \\
18 \\
\end{array}$} & \multirow{2}{*}{$\begin{array}{c}\text { Corresponding } \\
\text { percentage }\end{array}$} \\
\hline 0 & Normal Doppler & & \\
\hline 1 & Increased umbilical artery PI without other Doppler abnormalities & 28 & 17.5 \\
\hline 2 & $\begin{array}{l}\text { Increased umbilical artery PI with reduced middle cerebral artery PI - cerebroplacental } \\
\text { reversal }\end{array}$ & 86 & 53.8 \\
\hline 3 & Absent/reversed diastolic flow in umbilical artery with decreased middle cerebral artery $\mathrm{PI}$ & 14 & 8.8 \\
\hline 4 & Absent/reversed diastolic flow in umbilical artery with increased middle cerebral artery PI & 9 & 5.6 \\
\hline 5 & Altered 'a' wave in ductus venosus & 5 & 3.1 \\
\hline
\end{tabular}

\begin{tabular}{|l|c|c|c|c|c|c|c|}
\hline Perinatal outcome & Grade 0 & Grade 1 & Grade 2 & Grade 3 & Grade 4 & Grade 5 & Total \\
\hline IUD & 0 & 0 & 0 & 0 & 1 & 3 & $4(3 \%)$ \\
\hline Stillborn & 0 & 0 & 0 & 0 & 2 & 0 & $2(1 \%)$ \\
\hline Neonatal death & 0 & 0 & 0 & 2 & 4 & 2 & $8(5 \%)$ \\
\hline Increased perinatal morbidity & 0 & 0 & 16 & 11 & 2 & 0 & $29(18 \%)$ \\
\hline No adverse perinatal outcome & 18 & 28 & 70 & 1 & 0 & 0 & $117(73 \%)$ \\
\hline
\end{tabular}

GRADE 0 - NORMAL DOPPLER
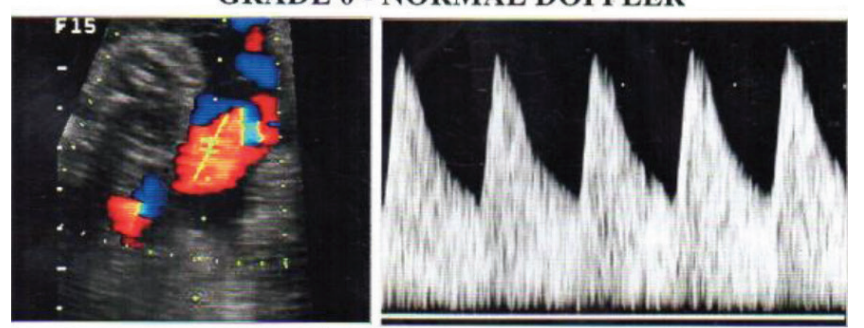

UMBILICAL ARTERY

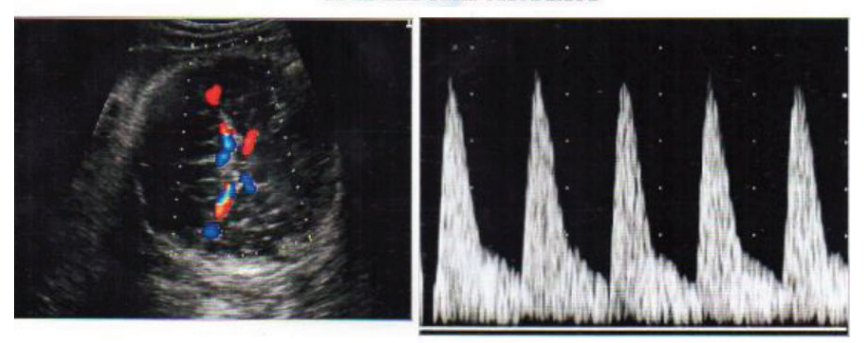

MIDDLE CEREBRAL ARTERY

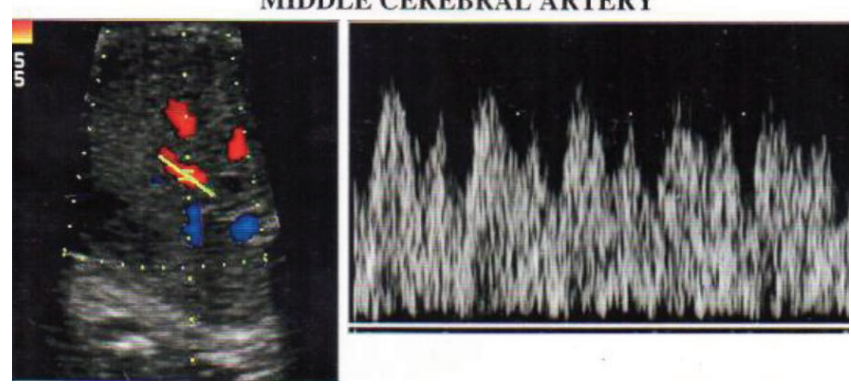

Figure-1: Grade 0 or normal Doppler showing low resistance flow pattern in the umbilical artery, high resistance flow in the MCA and the forward s, d and a waves in the ductus venosus

\section{some observations were made.}

Amongst our 160 patients, abnormal Doppler was observed in 142 patients. Only 18 out of our 160 patients had a normal Doppler pattern (Table 1).

Since the timing of obstetric intervention was based on a multifactorial dataset of Doppler abnormalities, to make the decision simpler, we had done a grading of the Doppler

\section{GRADE - 5: DUCTUS VENOSUS ALTERATION}

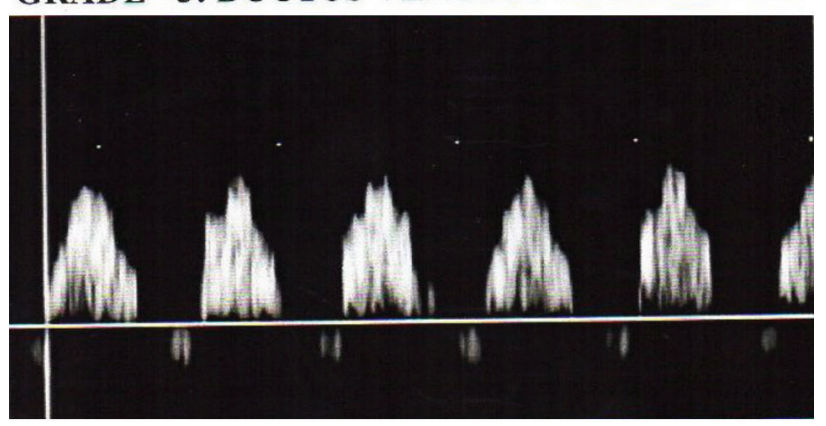

UMBILICAL ARTERY

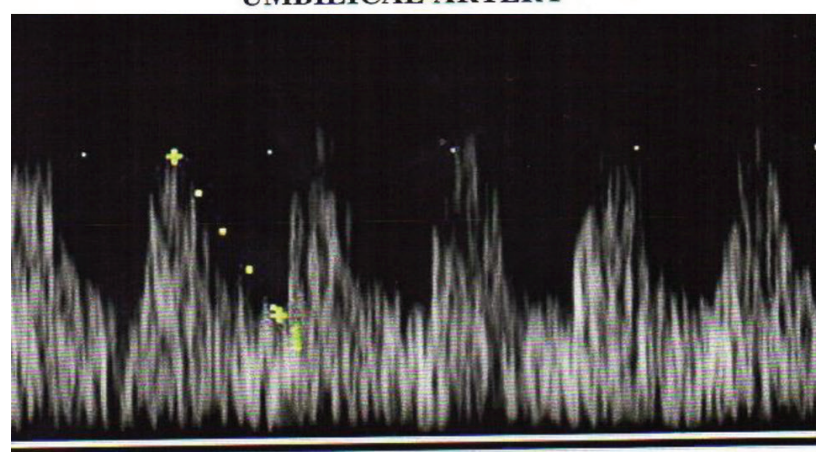

MIDDLE CEREBRAL ARTERY

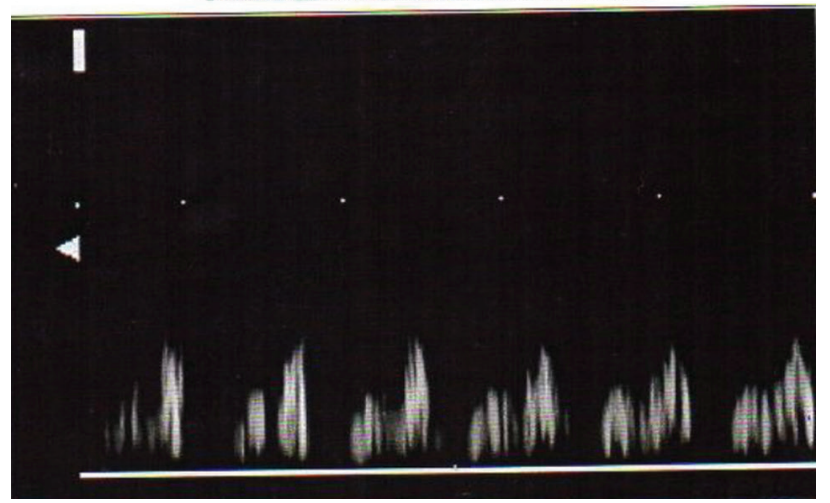

Figure-2: Grade 5 Doppler. Reversed diastolic flow in umbilical artery, compensated low resistance flow in the umbilical artery, absent a wave in ductus venosus 
abnormalities in the ascending order of severity ${ }^{20}$. This was done into six datasets from Grade 0 to Grade 5 as shown in Table 2.

In our 142 patients with positive Doppler findings, 28 patients were in Grade 1, 86 were in Grade 2, 14 patients were in Grade 3, 9 patients were in Grade 4 and 5 patients were in Grade 5 which indicated irreversible fetal acidemia (Table 3)

Figure 1 demonstrates the normal Doppler waveform of the umbilical artery, MCA and Ductus venosus, that is Grade 0. Figure 2 demonstrates the most severe Grade 5 Doppler waveform of the umbilical artery, MCA and ductus venosus.

\section{Perinatal outcome}

Out of the 160 cases, 146 were live born, 14 were neonatal deaths. There were 4 cases of intrauterine deaths and two were stillborn. Of the 146 live born, 29 had increased perinatal mortality which encompassed poor APGAR scores, necrotizing enterocolitis, hypoxic ischemic encephalopathy, meconium aspiration syndrome, hyperbilirubinemia and prolonged admission in NICU (Table 4).

\section{DISCUSSION}

Diagnosing IUGR is by B mode biometry. But the fetal hemodynamic status and hence the prediction of perinatal outcome requires a dedicated fetal Doppler study.

Ductus venosus Doppler in predicting and preventing fetal acidemia in confirmed growth restricted fetuses were analyzed in our study and we came to a few illuminating conclusions.

Amongst the Grade 0 fetuses, that is when the fetal Doppler is normal, there was no adverse perinatal outcome. So Grade 0 had a negative predictive value of $100 \%$.

Amongst the Grade 1 fetuses, when the only abnormality was a decrease in umbilical artery diastolic flow, again none of the fetuses had an adverse perinatal outcome. Hence, Grade 1 too had a negative predictive value of $100 \%$.

Grade 2 fetuses showed a cerebroplacental reversal. There was a flow compensation occurring in the fetus with preferential shunting of blood to the brain. Grade 2 had a negative predictive value of $84 \%$.

Grade 3 fetuses had no forward flow during diastole in the umbilical artery. Out of 14 fetuses in Grade 3, only one infant had no adverse perinatal outcome. There was a perinatal morbidity in 11 newborns with two neonatal deaths.

Grade 4 decompensated fetuses had a 100\% positive predictive value for adverse perinatal out come, with both perinatal morbidity and mortality.

Grade 5 fetuses, that is once there is increased resistance to flow in the ductus venosus, none of the fetuses survived. This grade therefore had a $100 \%$ positive predictive value as well as a $100 \%$ mortality $^{20}$.

It was obvious in our study therefore that all patients with a severe grade of abnormality (Grade 3 and above) had a worse outcome as compared to the patients in the lower grades of abnormality.

An inference from this study is a mild fetal hemodynamic compromise (Grade 1, Grade 2) had no significant perinatal mortality. Some Grade 2 fetuses had an increased perinatal morbidity, but survived with management.

Grade 3 and Grade 4 fetuses, where the fetus went in for decompensation and hypoxemia, there was a significant increase in perinatal morbidity, with a high mortality rate in Grade 4.

All 5 fetuses in Grade 5 did not survive, and this grade indicated fetal acidemia. The crucial combined role of the radiologist and gynecologist would be to regularly and closely monitor such high risk pregnancies with fetal Doppler, and intervene swiftly before the fetus progresses to Grade 4 Doppler abnormalities.

\section{CONCLUSION}

We conclude with this study, that with ductus venosus evaluation detection of fetal acidemia is possible. Once Doppler is normal, unnecessary pregnancy interventions should be avoided.

With our study, it has been definitively shown that ductus venosus alteration causes irreversible fetal compromise, and inevitably leads to fetal demise. Therefore close surveillance is crucial to deliver before the fetus turns acidotic, which is shown by altered "a" wave in ductus venosus which increases the pulsatility index.

Thus, we conclude, that Doppler can be used as a prognostic tool in an IUGR fetus, as it gives an accurate prediction of the potential compromise in varying degrees of severity.

\section{REFERENCES}

1. Divon and HSU. Maternal and fetal blood flow velocity waveforms in intrauterine growth retardation. Clin. Obste. Gynecol. 1992; 35(2): 156.

2. Warkany et al. Intrauterine growth retardation. Am. J. Dis. Child 1961;102(2):24.

3. Gruenwald. Chronic fetal distress and placental insufficiency. Biol. Neonate 1963;5(4): 215.

4. Battaglia et al. A practical classification of newborn infants by weight and gestational age, J. Pediatr 1967; 17(5): 159.

5. Manning et al., 1991. Intrauterine growth retardation. Diagnosis, Prognostication, and Management based on Ultrasound methods, Principles and Practices of Ultrasonography in Obstetricsand Gynaecology, 4th ed. 1991.

6. Rajan R. 2001. TLTGR, Ultrasound in human reproduction 2nd Edition, 10-23.

7. Lubchenco, et al. Intrauterine growth as estimated from liveborn birth - weight data at 24 to 42 weeks of gestation Pediatrics 1963;32(2): 793.

8. Seeds et al. Impaired fetal growth - Definition and Clinical diagnosis Obstet. Gynecol 1998; 64(3): 303.

9. Gardosi, et al., 1992. Customized antenatal growth charts, Lancet 1992;339(6): 283.

10. Seeds. Impaired fetal growth. Definition and Clinical Diagnosis. Obstet. Gynecol 1984;64(1): 303.

11. Usher and McLean. Intrauterine growth of live born caucasian infants at sea level. J. Pediatr 1969;74(5): 901.

12. Mclntrie et al. Birthweight in relation to morbidity and mortality among newborn infants. N. Engt J. Med 1999;340(7): 1234.

13. Manning 1995. Intrauterine growth retardation. In fetal 
Medicine Principles and Practice, 1995, p.317.

14. Owen et al. Fetal size and growth velocity in the prediction of intrapartum cesarean section for fetal distress. Br. J. Obstet. Gynecol 1997;1904(3):445.

15. Owen et al. Fetal growth velocity in the prediction of intrauterine growth restriction in a low risk population. Br. J. Obstet. Gynaecol 1998;105:536.

16. Paz et al., Cognitive outcome of full term small - for gestational age infants at late abdolescent. Obstet. Gynecol 1995;85:452.

17. Piper et al. Do growth retarded prematare infants have different rates of perinatal mobidity? Obstet. Gyriecol 1996;87(5): 169.

18. Kleigman, 1997. Intrauterine growth retardation. Neonatal Perinatal Medicine, 6th ed. 1997 - p.203.

19. Nicolaides et al., 1991. Cordocentesis in the study of growth retarded features. In Divon MY (ed): Abnormal Fetal growth - 1991.

20. Anita. S et al. A study of Doppler Prediction of Adverse Perinatal Outcome in Growth Restricted Fetuses Sch. J. App. Med. Sci 2017; 5(2):422-426.

Source of Support: Nil; Conflict of Interest: None

Submitted: 13-05-2018; Accepted: 17-06-2018; Published online: 24-06-2018 